\title{
Assessment of Work-related Stress in Brunei Public and Private Sector Employees
}

\author{
Lawrence Mundia \\ Psychological Studies and Human Development Academic Group, Sultan Hassanal \\ Bolkiah Institute of Education, Universiti Brunei Darussalam, Jalan Tungku Link, Gadong \\ BE 1410, Bandar Seri Begawan, Brunei Darussalam \\ E-mail: lawrence.mundia@ubd.edu.bn
}

Received: Nov. 7, 2019 Accepted: Dec. 5, 2019 Online published: Dec. 22, 2019

doi:10.5296/jpag.v9i4.16100ＵRL: https://doi.org/10.5296/jpag.v9i4.16100

\begin{abstract}
The aim of the present study was to investigate the prevalence of stress in work situations for 860 randomly selected Brunei public and private sector employees of both genders. A quantitative field survey was used to probe the problem. This strategy's main difference and advantage compared to postal, telephone and online survey procedures was that it enabled an immediate collection of data onsite. Work-related stress was prevalent in Brunei public and private sector employees. Employees with low and middle level education were the most affected by work stress. In addition, workers who lived with parents and the chief income earners in the households were also distressed. Incorporation of an interview component would have helped in triangulation and interpretation of the survey findings. Prolonged and untreated work-related stress poses a high likelihood risk of lowering the quantity and quality of productivity in any work environment. Appropriate individual and group interventions (educational, counseling and psychotherapy) for vulnerable employees at risk of developing work-related stress problems were recommended. In addition, further research with interview probes was also desired to address the problem. To promote holistic employee mental health well-being, the labor force needs to operate in none-stressful work-places and live in stress-free contexts.
\end{abstract}

Keywords: stress, employees, public sector, private sector, Brunei

\section{Introduction}

Stress is generally believed to be the body's physical and mental responses to demands made upon it and is often the result of a person's reaction to outside events (see Selye, 1974). According to Selye, not all stress is bad. There is both bad and good stress. Good stress, also known as eustress, is mild or moderate and energizes people to be proactive (Selye, 1974). 
Stressors can be either positive or negative events (or both). Multiple theories generally divide the stress problem into four stages: onset of the stressor; appraisal; reaction; and long-term strain on health. When the distress sets in, the sufferer goes through all four steps, and people differ considerably in the way they address each stage. Regardless of how a person appraises and reacts to stressors, there are long-term strains on an individual's health. For example, a person working long hours without proper rest may develop heart problems, while a laborer who carries heavy objects every day may develop back problems. The psychological strains will eventually affect the physiology and ultimately the biology of a person over a long time. In terms of physical health, too much stress could lead to cardiovascular diseases, digestive problems, and headaches as well as weaken the immune system, thereby making the individual vulnerable to infection. When people experience overwhelming stress for a long time and are unable to deal with it, the condition may lead to depression and suicide. Although stress is inevitable at work, it can be managed to minimize its harmful effects. Apart from damaging health, stress can also have a negative impact on a person's performance and productivity at the workplace. A study by Porter and Steers (1973) showed that poor employee performance and absenteeism were linked to worker stress. This is more so for workers with low education who do physically demanding jobs (Park, 2008). Stress has a wide range of effects. The many different types of stress include post-traumatic stress disorder (PTSD); optimal stress (eustress); adaptive stress; negative stress; acute stress; and chronic stress. There are equally several different symptoms of stress that include burnout; headaches/migraines; hypertension; intolerance, irritability; tension; ulcers; stroke; insomnia; and impotence/sexual dysfunction. In addition, stress is also somehow related to depression and anxiety (Andrews and Wilding, 2004; Bouteyre et al., 2007).

\subsection{Past Research on Brunei Work Environments}

Not much research has previously been conducted on stress among employees in Brunei. This is the first time a large-scale research was done about stress in public and private sector workers in Brunei. Past research of a psychological nature had addressed a number of other problems such as various disabilities (Bradshaw \& Mundia, 2005; Bradshaw \& Mundia, 2006; Tait \& Mundia, 2012a, b; Haq \& Mundia, 2012; Mundia, 2006; Yusuf \& Mundia, 2014; Tait \& Mundia, 2014; Tait, Mundia, \& Fung, 2014; Tait, Mundia, Fung, \& Wong, (2014). Besides disability, previous research also examined the mental health concerns of students in the education system (Mundia 2010a; Mundia, 2010b; Mundia 2012a, b; Mundia, 2013; Mundia, 2015). Most of the teaching and learning research on Brunei has focused on a wide range of school subjects including mathematics and Japanese language (Mundia, 1998; Mundia, 2010c; Mundia, 2010d; Mundia, 2007; Mundia, 2009; Mundia, 2011a; Mundia, 2012c; Keaney \& Mundia, 2014; Mundia \& Metussin, 2019). The training of teachers was also accorded priority by research (e.g. Mundia, 2012d, e; Tait \& Mundia, 2012b; Tait \& Mundia, 2014). Problems associated with conducting research using Brunei student samples were investigated by two studies (see Mundia \& Bakar, 2010; Mundia, 2011b). Issues related to common methods bias in research using Brunei samples were reported in two studies (Mundia, 2019a; Mundia, 2019b). The scarecity of and need for research on stress in Brunei work environments provided the rationale and justification to conduct the current study. 


\subsection{Contributors of Work-Related Stress in Brunei Public and Private Sector Employees}

There are many factors that contribute to work-related stress in Brunei public and private sector employees. Due to scarcity of research on the issue, the direct causal factors (also known as stressors) are not known in the Brunei context. However, besides the stressful demands of any job, there was indirect evidence from recent studies that the responsibility and pressure to support the family were partly elements of work-related stress (Author et al., 2016a, 2016b, 2017). In addition, research has also linked family conflicts to work-related stress (Jamadin et al., 2015). Jex (2002) defined a stressor as an aspect of the environment that requires some adaptive behavior from the individual. Some of the major causes of work-related stress include job content, workload and work pace, working hours, participation and control, stagnant career development, and home-work interference (Leka et $a l ., 2004)$. It is quite possible that the following factors (which need to be probed by future interview research) may cause stress in Brunei employees in different work contexts: doing a demanding task; conflicts with co-workers; not getting along well with the boss; interpersonal communication problems; dissatisfaction with working conditions, such as low pay; disappointments with work-related achievements; lack of promotion or progress; procrastinating or leaving work assignments to the last minute; adjusting to life in a new work environment; excessive and unrealistic workload; long hours of work; being a workaholic; doing difficult work without proper training and abilities; repeated failure and lack of experience with success; poor health; role of biological factors (e.g., stress hormones and the autonomic nervous system); and drugs. This list is not exhaustive but rather illustrative of the potential causal factors that need to be investigated in the Brunei work environments.

\subsection{Assessment of Stress}

There are several instruments that measure stress. The examples of instruments used include the Occupational Stress Inventory (Osipow and Spokane, 1987), the Maslach Burnout Inventory (Maslach and Jackson, 1986), Ways of Coping Questionnaire (Folkman and Lazarus, 1988), the Stress Appraisal Measure (Peacock and Wong, 1990), and the Depression, Anxiety and Stress Scale, DASS (Lovibond and Lovibond, 1995). The items and contents of the instrument used in the present study were mostly constructed by the researcher, but some were adapted from several literature sources.

\subsection{Objectives of the Study}

The purpose of the present pioneer study was to investigate and determine the influence of selected demographic variables on work-related stress in Brunei public and private sector employees. This is the first time stress is investigated in detail in Brunei government and company workers. The findings may be helpful in informing policy makers to devise appropriate intervention programs for vulnerable employees at risk of acquiring work-related stress.

\section{Method}

The design, participants, instruments, data analysis techniques, and procedures used in this 
study are briefly explained separately below.

\subsection{Design}

A quantitative field survey was used, as this strategy could handle a large sample from which required data would be collected directly from participants within a short time. Other types of survey research (e.g., postal, online, telephone, and longitudinal) do not have such supportive structures.

\subsection{Participants}

According to the Department of Economic Planning and Development (2015), there were 189,500 employed persons in Brunei in 2014 comprising of 108,500 males (57.3\%) and 81,000 females (42.7\%). Of these, 137,300 (72.5\%) were local Brunei citizens for whom the current study was designed, while 52,200 (27.5\%) were foreigners. Although the numbers were not shown in this report, the public sector employed far more people than the private sector. A list of Government Ministries and Departments located throughout Brunei was obtained from the Prime Minister's Office as a sampling frame for public employee participants. A separate list of companies operating in Brunei-Muara District (the metropolitan area with the largest population and most private companies in the country) was made by the researcher and used as a sampling frame for private sector employee participants. Once the relevant total population was known, determining the appropriate random sample size for a study required the use of either a formula, such as the ones employed by Yamane (1967) and Chand et al. (2012), or a table of population values and corresponding sample sizes, such as the one developed by Krejcie and Morgan (1970). Such formulas or tables indicate the number of required participants in a study for the researcher(s) to compute stable statistics that show acceptable significant relationships or differences between the independent and dependent variables at either $p=0.05$ or $p=0.01$. No formula was used in the current study. However, since the population of interest to whom the results of the present study could be generalized was 137,300, a minimum random sample of $\geq 384$ was considered sufficient for our research according to the population and sample size table of Krejcie and Morgan (1970). Using the simple random sampling technique, 822 participants (instead of 384) were recruited for the study from different Ministries and Departments in the public sector throughout Brunei. Unfortunately, only 38 persons were recruited from the private sector due to potential participants' lack of interest to volunteer for the study. The two selections gave a composite sample of 860 labor force participants from both sectors of the Brunei economy (public and private). Based on 4-point inclusion criteria, only those people who met the following conditions were selected: (1) persons of all genders, ethnicities, religions, and age were acceptable; (2) full Brunei citizens or permanent residents; (3) employed in the public or private sector; and (4) willingly volunteer to participate in the study. No other inclusion and exclusion criteria were applied. The demographic composition and personal characteristics of the selected participants are presented in Table 1. On some variables and analyses, the sample fails to reach 860 due to missing values. 
Table 1. Participants' Demographic Information $(\mathrm{N}=860)$

\begin{tabular}{|c|c|c|c|}
\hline Variable & Gender & Number $(\%)$ & Mean (SD) \\
\hline \multirow[t]{3}{*}{ Age } & All & $860(100 \%)$ & $37.690(9.045)$ \\
\hline & Females & $613(71.300 \%)$ & $37.690(9.262)$ \\
\hline & Males & $247(28.700 \%)$ & $37.710(8.516)$ \\
\hline \multirow[t]{5}{*}{ Race } & Group & Frequency & Percentage \\
\hline & Malay & 810 & 94.200 \\
\hline & Chines & 25 & 2.900 \\
\hline & Others & 22 & 2.600 \\
\hline & Missing & 1 & 0.300 \\
\hline \multirow[t]{4}{*}{ Religion } & Muslim & 837 & 97.300 \\
\hline & Non-Muslim & 12 & 1.400 \\
\hline & No religion & 10 & 1.200 \\
\hline & Missing & 1 & 0.300 \\
\hline \multirow[t]{3}{*}{ Citizenship } & Brunei citizen & 831 & 96.600 \\
\hline & Permanent resident & 26 & 3.000 \\
\hline & Missing & 3 & 0.400 \\
\hline \multirow[t]{5}{*}{ Education } & Low (Primary to Year 13) & 362 & 42.100 \\
\hline & Middle (Post-secondary to diploma) & 194 & 22.600 \\
\hline & High (Bachelor's degree to doctoral & 301 & 35.000 \\
\hline & degree) & 3 & 0.300 \\
\hline & Missing & & \\
\hline \multirow[t]{2}{*}{ Employer } & Public sector (government) & 822 & 95.600 \\
\hline & Private sector (non-government) & 38 & 4.400 \\
\hline \multirow[t]{3}{*}{ Marital status } & Single (never married) & 221 & 25.700 \\
\hline & Married & 615 & 71.500 \\
\hline & Divorced (17)/widowed (7) & 24 & 2.800 \\
\hline \multirow{3}{*}{$\begin{array}{l}\text { Do you have } \\
\text { children? }\end{array}$} & Yes & 571 & 66.400 \\
\hline & No & 286 & 33.300 \\
\hline & Missing & 3 & 0.300 \\
\hline \multirow[t]{5}{*}{ District } & Brunei-Muara & 721 & 83.800 \\
\hline & Tutong & 104 & 12.100 \\
\hline & Kuala Belait & 20 & 2.300 \\
\hline & Temburong & 10 & 1.200 \\
\hline & Missing & 5 & 0.600 \\
\hline
\end{tabular}




\begin{tabular}{llll} 
Who do you live & Alone & 27 & 3.100 \\
with & Parents & 296 & 34.400 \\
& In-laws & 57 & 6.600 \\
& Family members (siblings) & 73 & 8.500 \\
& Spouse and children & 384 & 44.700 \\
& Missing & 23 & 2.700 \\
Do you stay/live & Yes & & \\
in your own & No & 502 & 58.400 \\
house & Missing & 356 & 41.400 \\
Are you the chief & Yes & 2 & 0.200 \\
wage earner in & No & & \\
your household? & Missing & 282 & 32.800 \\
\hline
\end{tabular}

\subsection{Instruments}

The study used two instruments (a demographic questionnaire and a stress scale), both constructed by the researcher. The 16-item demographic questionnaire collected the participants' personal biographic information, as reported in Table 1. The 5-item stress questionnaire was one of the scales that the author developed from a pool of 28 items that formed four questionnaires measuring employees' workplace problems such as work-related stress, interpersonal communication problems, employer-employee relationship problems, and work-attendance problems. The items in these four questionnaires were derived from five main sources, namely: (1) items adapted from the Interpersonal Trust Scale (Rotter, 1967), the Value Survey (Rokeach, 1967) and the Goal and Mode Values Inventories (Braithwaite and Law, 1985); (2); modified items from the World Values Survey (The Social Research Centre \& Australian National University, 2012), which are available online for free download and use; and (3) the researchers' own constructed items based on content review of the relevant literature as well as the author's personal conceptualization of these problems in the Brunei context. Of these four instruments, the present study used only the work-related stress questionnaire. All five items in this questionnaire were rated on 5-point Likert scales (e.g., Please rate the frequency of the following problems you have faced or are facing at work: Conflicts and not getting along with co-workers or supervisor or boss. Select one of the following options for your response: 1 Never; 2 Rare; 3 Sometimes; 4 Often; 5 Always).

The items adapted from Rotter (1967), Rokeach (1967) as well as Braithwaite and Law (1985) are available in Robinson et al.'s (1991) book, and researchers are free to use items from various scales contained in this book provided full acknowledgement is made. In addition, researchers are also permitted to make adaptations, modifications, or changes to the items (to suit their contexts) without written permission from the copyright owners. Two main changes were made to all the borrowed items: (1) wording or phrasing of the item statements/stems; and (2) the response and scoring formats of the items. All the items were worded positively and did not require reverse scoring. Each participant's total scale score was simply the sum of 
all the item nominal values endorsed. Because of extensive changes made to the borrowed items and inclusion of a few items composed by the author/researcher, the 28 items were subjected to principal components exploratory factor analysis (EFA) with varimax rotation to determine the four latent factors or scales the items represented. The naming of the factors or scales was largely based on content analyses of the item descriptions in the Brunei linguistic and cultural context. Evidence in Table 2 indicates that the four scales were reliable.

Table 2. Scale Statistics, Alpha Reliability and Construct Validity $(\mathrm{N}=860)$

\begin{tabular}{|c|c|c|c|c|c|c|c|c|c|c|c|c|}
\hline $\begin{array}{l}\text { EFA }^{a} \text { Factor/Scale } \\
\text { Name }\end{array}$ & Items & Mean & $\mathrm{SEm}^{\mathrm{b}}$ & $\mathrm{SD}^{\mathrm{c}}$ & Median & $\begin{array}{l}\text { Average } \\
\text { CITSr }^{\mathrm{d}}\end{array}$ & $\begin{array}{l}\text { Cronbach } \\
\text { Alpha }\end{array}$ & $\begin{array}{l}\% \\
\text { Variance } \\
\text { Accounted }\end{array}$ & $\mathrm{KMO}^{\mathrm{e}}$ & $\begin{array}{l}\mathrm{BTS}^{\mathrm{f}} \\
\chi^{2}\end{array}$ & $\mathrm{df}$ & Sig. \\
\hline $\begin{array}{l}\text { Employees'workplace } \\
\text { problems }\end{array}$ & 28 & & & & & & & & & & & \\
\hline $\begin{array}{l}\text { Factor } 1 \text { - Interpersonal } \\
\text { communication } \\
\text { problems }\end{array}$ & 11 & 38.440 & 0.297 & 8.716 & 40.000 & 0.649 & 0.880 & 22.860 & 0.940 & 15683.138 & 378 & $<0.000$ \\
\hline $\begin{array}{l}\text { Factor } 3 \text { - Work-related } \\
\text { stress problems }\end{array}$ & 5 & 12730 & 0.139 & 4.062 & 13.000 & 0.585 & 0.865 & 13.107 & & & & \\
\hline $\begin{array}{l}\text { Factor } 4 \text { - Work } \\
\text { attendance problems }\end{array}$ & 4 & 13.310 & 0.132 & 3.882 & 14.000 & 0.611 & 0.825 & 10.892 & & & & \\
\hline Total variance & - & - & - & - & - & - & - & 64.107 & & & & \\
\hline
\end{tabular}

${ }^{\mathrm{a}} \mathrm{EFA}=$ Exploratory factor analysis; $\quad{ }^{\mathrm{b}} \mathrm{SEm}=$ Standard error of the mean; ${ }^{\mathrm{c}} \mathrm{SD}=$ Standard deviation; ${ }^{\mathrm{d}} \mathrm{CITSr}=$ Average Corrected Item-to-Scale correlation; ${ }^{\mathrm{e}} \mathrm{KMO}=$ Kaiser-Meyer-Olkin measure of sampling adequacy; ${ }^{\mathrm{f}} \mathrm{BTS}=$ Bartlett's test of sphericity

Furthermore, the scales had sufficient construct validity as revealed by the percentages of common variance explained. Moreover, the Kaiser-Meyer-Olkin measure of sampling adequacy (KMO) and Bartlett's chi-square test of sphericity (BTS $\chi^{2}$ ) showed that the performed EFA was satisfactory and suited the data. Low scorers on the work-related stress scale were interpreted as signifying little or no stress problems. Above all, the following low but significant (all $\mathrm{p}<.01)$ correlations were obtained with work-related stress: interpersonal communication problems (0.576); employer-employee relationship problems (0.642); and work attendance problems (0.424). These correlation coefficients demonstrate quantitative evidence of discriminant validity for the work-related stress questionnaire.

\subsection{Data Analysis}

All the independent (sociodemographic) variables were categorical. The dependent (work-related stress problems) variable was dichotomized at the median to also be categorical. The quantitative data were then analyzed using descriptive statistics (frequencies, percentages, mean, and standard deviation) and inferential statistics (hierarchical binary logistic regression analysis with backward elimination). To determine the importance of the findings, two-tailed tests of statistical significance at both $p=0.05$ and $p=0.01$ levels and tests of statistical power (such as effect sizes and model fit chi-square indices for binary logistic regression analyses) were used. All the statistical analyses were performed on SPSS Version 22.

\subsection{Procedures}

The present study was funded by the Brunei Research Council (BRC) in the Government of 


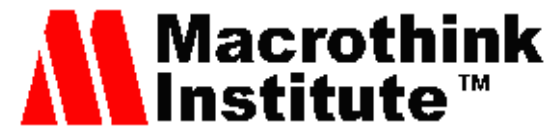

Journal of Public Administration and Governance

ISSN 2161-7104

2019, Vol. 9, No. 4

Brunei Darussalam through the University of Brunei Darussalam (UBD), a state tertiary institution. Written permission and approval to conduct the study were obtained from the University of Brunei Darussalam Ethics Committee as well as the Brunei Research Council Ethics Committee on behalf of the Government of Brunei Darussalam. In addition, ethical conditions and rights (e.g., anonymity, confidentiality, privacy, voluntary participation, protection from harm, and informed consent) for participating in the study were explained verbally in either English or Bahasa Melayu language to individual research participants prior to collecting the data. Verbal and written informed consent were then secured from each research participant in either of the two languages at the time and place of collecting the data. Only persons who voluntarily agreed to participate in the study were recruited. Coercion and deception were not used when recruiting the participants. Names of government ministries, departments and companies that constituted the sampling framework are not revealed to conceal the identity of the participants. To guarantee anonymity and confidentiality, all the data were analyzed at the group level. Furthermore, all the study's research tools were written in simple English language requiring only Grade 7 or Year 7 level of education. To address and reduce any possible linguistic and cultural biases, parallel bilingual items were presented on the instruments in both English and Bahasa Melayu, the main and official language of Brunei spoken by the majority of the people. Above all, data collection occurred in the participants' work environments to increase and enhance the study's ecological validity.

\section{Results}

The major findings of the present study are presented and explained below according to the main objective of the investigation.

\subsection{Relationship Between Sociodemographic Variables and Work-Related Stress}

To determine the relationships between sociodemographic variables (independent variables, IVs) and work-related stress (dependent variable, DV), Spearman correlation was used in the first stage. However, only educational level (a trichotomous variable) was appreciatively and significantly associated with work-related stress $[\mathrm{r}(860)=-0.162, \mathrm{p}<.01]$ but it was not clear from the negative correlation here which of the three parts of educational level (low, middle and high) was or were less involved with work-related stress. The rest of the obtained non-significant coefficients (not shown here) were low correlations (both positive and negative). These findings suggested the need to use more robust statistical analysis procedures (that were sensitive to minor differences in determining the relationships between sociodemographic variables and work-related stress to get significant and interpretable results). This was done in the second stage by employing the binary logistic regression analysis with backward elimination (that enabled the researcher to explore, identify and select predictors most relevant in the model).

The binary logistic regression analysis required a binary dependent variable (DV) and categorical independent variables (IVs). In the present study, the continuous DV (work-related stress) was dichotomized at the median score to make it binary. Low scorers were coded one (1), while higher scorers were coded zero (0). The IVs were sociodemographic variables. The findings of the binary logistic regression analysis are 
presented in Table 3. In Step 1 (also known as Model 1), all the IVs were entered and regressed on the DV. SPSS (Version 22) iteratively processed the data in 12 steps. For purposes of data reduction and space conservation, only the first and last models are shown in Table 3, which shows the specific contribution of each categorical IV to work-related stress. Step 1 (first model) was overfitted and less efficient because it contained both the needed and unwanted IVs. The unnecessary IVs had relatively higher standard errors. In the subsequent models, SPSS hierarchically removed the irrelevant terms in a stepwise manner.

Table 3. Detailed Relationships between Sociodemographic Variables and Work-Related Stress from Binary Logistic Regression Analysis ( $\mathrm{N}=860) \#$

$95 \%$ CI for AOR

Wald

Model $\uparrow \quad$ B $\quad$ SE $\chi^{2} \quad$ df $\quad$ Sig. $\quad$ AOR $^{\text {e }}$ Lower Upper

Step 1

Males

Private employer

Educational level

Low education ${ }^{\mathrm{a}}$

Middle education ${ }^{\mathrm{b}}$

Sought help from counselors (Yes)

Sought help from family members (Yes)

\begin{tabular}{|c|c|c|c|c|c|c|c|}
\hline-0.035 & 0.194 & 0.033 & 1 & 0.856 & 0.965 & 0.660 & 1.412 \\
\hline \multirow[t]{2}{*}{-0.434} & 0.365 & 1.411 & 1 & 0.235 & 0.648 & 0.317 & 1.325 \\
\hline & & 17.227 & 2 & $0.000 * *$ & & & \\
\hline 0.708 & 0.172 & 16.914 & 1 & $0.000 * *$ & 2.030 & 1.449 & 2.845 \\
\hline 0.445 & 0.195 & 5.198 & 1 & $0.023^{*}$ & 1.561 & 1.064 & 2.290 \\
\hline-0.432 & 0.279 & 2.392 & 1 & 0.122 & 0.649 & 0.375 & 1.122 \\
\hline 0.044 & 0.224 & 0.038 & 1 & 0.845 & 1.045 & 0.674 & 1.620 \\
\hline 0.008 & 0.177 & 0.002 & 1 & 0.965 & 1.008 & 0.712 & 1.427 \\
\hline 0.166 & 0.748 & 0.049 & 1 & 0.825 & 1.180 & 0.273 & 5.110 \\
\hline-0.195 & 0.159 & 1.505 & 1 & 0.220 & 0.823 & 0.603 & 1.123 \\
\hline-0.445 & 0.334 & 1.775 & 1 & 0.183 & 0.641 & 0.333 & 1.233 \\
\hline \multirow[t]{2}{*}{0.133} & 0.197 & 0.453 & 1 & 0.501 & 1.142 & 0.776 & 1.681 \\
\hline & & 0.580 & 2 & 0.748 & & & \\
\hline 0.175 & 0.554 & 0.100 & 1 & 0.752 & 1.191 & 0.402 & 3.529 \\
\hline 0.309 & 0.484 & 0.408 & 1 & 0.523 & 1.362 & 0.528 & 3.516 \\
\hline \multirow[t]{2}{*}{-0.042} & 0.272 & 0.023 & 1 & 0.879 & 0.959 & 0.563 & 1.635 \\
\hline & & 11.394 & 4 & $0.022 *$ & & & \\
\hline-0.442 & 0.457 & 0.933 & 1 & 0.334 & 0.643 & 0.263 & 1.575 \\
\hline 0.428 & 0.204 & 4.401 & 1 & $0.036^{*}$ & 1.534 & 1.029 & 2.289 \\
\hline 0.131 & 0.300 & 0.191 & 1 & 0.662 & 1.140 & 0.633 & 2.051 \\
\hline \multirow[t]{2}{*}{-0.390} & 0.296 & 1.739 & 1 & 0.187 & 0.677 & 0.379 & 1.209 \\
\hline & & 0.500 & 3 & 0.919 & & & \\
\hline-0.009 & 0.690 & 0.000 & 1 & 0.989 & 0.991 & 0.256 & 3.835 \\
\hline-0.139 & 0.716 & 0.038 & 1 & 0.846 & 0.870 & 0.214 & 3.541 \\
\hline-0.208 & 0.833 & 0.063 & 1 & 0.802 & 0.812 & 0.159 & 4.15 \\
\hline 0.359 & 0.187 & 3.686 & 1 & 0.055 & 1.432 & 0.993 & 2.067 \\
\hline
\end{tabular}

Sought help from prayer/religion (Yes)

Sought help from Bomo ${ }^{c}$ (Yes)

Sought help from friends (Yes) df Sig. $\mathrm{AOR}$

Sought help from online social networking (Yes)

Sought help from Ustad ${ }^{\mathrm{d}}$ (Yes)

Marital status

Single

Married

Do you have children? (Yes)

Who do you live with?

Live alone

Live with parents

Live with in-laws

Live with siblings

District

Brunei-Muara

Tutong

Kuala Belait

Are you the chief wage earner in your household? (Yes) 
Step 12

Educational level

Low education $^{\mathrm{a}}$

Middle education ${ }^{\mathrm{b}}$

Sought help from counselors (Yes)

Who do you live with?

Live alone

Live with parents

Live with in-laws

Live with siblings

Are you the chief wage earner in your household? (Yes)

$22.29820 .000 * *$

$\begin{array}{llllllll}0.780 & 0.165 & 22.263 & 1 & 0.000^{* *} & 2.182 & 1.578 & 3.018 \\ 0.438 & 0.192 & 5.198 & 1 & 0.023 * & 1.550 & 1.063 & 2.258 \\ -0.468 & 0.270 & 3.002 & 1 & 0.083 & 0.626 & 0.369 & 1.063 \\ & & 11.825 & 4 & 0.019 * & & & \\ -0.544 & 0.428 & 1.616 & 1 & 0.204 & 0.581 & 0.251 & 1.343 \\ 0.347 & 0.163 & 4.571 & 1 & 0.033 * & 1.415 & 1.029 & 1.946 \\ 0.115 & 0.294 & 0.152 & 1 & 0.696 & 1.121 & 0.631 & 1.994 \\ -0.451 & 0.276 & 2.682 & 1 & 0.101 & 0.637 & 0.371 & 1.093 \\ 0.342 & 0.157 & 4.774 & 1 & 0.029 * & 1.408 & 1.036 & 1.914\end{array}$

Low education $^{\mathrm{a}}=$ Primary school to General Certificate of Education Advanced Level (GCE A-Level)

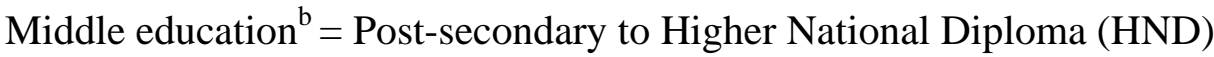

Bomo $^{c}=$ Traditional healer

Ustad $^{\mathrm{d}}=$ religious teacher/leader e.g. Imam (Muslim preacher)

$\mathrm{AOR}^{\mathrm{e}}=$ adjusted odds ratio

$* \mathrm{p}<.05$ (two-tailed)

$* * \mathrm{p}<.01$ (two-tailed)

$†$ Step 1: R Squares $=0.054$ (Cox \& Snell), 0.071 (Nagelkerke); Hosmer and Lemeshow $\chi^{2}(\mathrm{df}$ $=8)=7.401, \mathrm{p}=0.494$

$\dagger$ Step 12: R Squares $=0.046$ (Cox \& Snell), 0.062 (Nagelkerke); Hosmer and Lemeshow $\chi^{2}$ $(\mathrm{df}=8)=4.972, \mathrm{p}=0.761$

\#Dependent variable $=$ work-related stress scores

Though underspecified, Step 12 (last model) contained the four best, and statistically significant, predictors of work-related stress that had lower standard errors after adjusting for non-desirable variables. The suitable IVs were low education; middle education; living with parents; and being a chief wage earner in the family. The binary logistic model accounted for approximately $5-7 \%$ of the common variance between the IVs and DV in the first step and approximately $4-5 \%$ in the last step. The model was also acceptable as illustrated by the nonsignificant $\chi^{2}$ fit indices at the bottom of Table 3 .

Compared to workers with high education (reference group, $\mathrm{n}=301$, see Table 1 for frequencies and percentages), employees with a low education $(\mathrm{n}=362)$ were almost 2.2 times more likely to have work-related stress $(\mathrm{B}=0.780, \mathrm{p}<.01 ; \mathrm{AOR}=2.182,95 \% \mathrm{CI}=$ 1.578-3.018). However, employees with a middle education $(n=194)$ were only approximately 1.6 times more likely to have work-related stress problems compared to peers 
with high education, $\mathrm{n}=301(\mathrm{~B}=0.438, \mathrm{p}<.05 ; \mathrm{AOR}=1.550,95 \% \mathrm{CI}=1.063-2.258)$. Similarly, workers who lived with their parents $(\mathrm{n}=296)$ also had high likelihood of possessing work-related stress compared to counterparts who only lived with a spouse and own children (reference group with $\mathrm{n}=384)(\mathrm{B}=0.347, \mathrm{p}<.05$; $\mathrm{AOR}=1.415,95 \% \mathrm{CI}=$ 1.029 -1.946). In addition, an employee who was designated the chief wage earner in the family household $(\mathrm{n}=282)$ was more likely to have high adjusted odds ratios for work-related stress than those who were not the main bread earners, $\mathrm{n}=561(\mathrm{~B}=0.342$, $\mathrm{p}<.05 ; \mathrm{AOR}=1.408,95 \% \mathrm{CI}=1.036-1.914)$.

\section{Discussion}

The main results of the present study are briefly explained below according to the objective of the investigation. The statistically significant sociodemographic predictors of work-related stress in the present study (that were associated with having high adjusted odds ratios for stress) were low education, middle education, living with parents, and being a chief wage earner in the family.

\subsection{Educational Background}

In support of findings from the present study, previous research conducted in Canada showed that individuals with low education were more likely to have physically demanding and stressful jobs than workers with high education (Park, 2008). In turn, work-related stress often negatively impacts an employee's productivity (Porter and Steers, 1973). In Brunei, people with physically demanding and stressful jobs might include workers with middle level education according to findings of the current study. Both groups of lowly educated workers deserve appropriate stress interventions, which could be in form of education, counseling and psychotherapy (depending on the nature and degree of stress).

\subsection{Living With Parents}

The current study found that workers who lived with parents were more likely to have work-related stress problems. In the absence of interviews with probes, it was not clear why this was the case in Brunei. However, it was evident that most Bruneians live in large family groups. For example, a large nuclear family living in one large house may consist of parents, elderly married and working children, grandchildren, and great-grandchildren, including other next-of-kin relatives. In such an environment, it could be speculated that family conflicts do arise at certain times. It is thus quite possible that prolonged and unresolved family conflicts become stressful and eventually begin to negatively impact the work of employed family members. The stress-affected working family members need interventions to address their problems. This finding of the present Brunei study contradicts the outcomes of an investigation conducted by Jamadin et al. (2015) in Malaysia, a country whose culture (language and religion) are similar to Brunei's. In their study, Jamadin et al. (2015) found that people who were single and lived alone were prone to work-related stress compared to employees who were married. This was probably because married employees received help from and shared their responsibilities with spouses, whereas unmarried employees faced all problems and responsibilities by themselves (Jamadin et al., 2015). 


\subsection{Being a Chief Wage Earner in the Family Household}

The demanding and tedious task of caring for others in the family in terms of putting food on the table was quite a stressful responsibility in Brunei according to findings of the current study. As already stated above (see Section 4.2), the family sizes tend to be large and the demand for resources to sustain the family could be intense and challenging if there were not many workers in the household. The situation would be equally bad if the sole provider or few workers in the family earned only little money.

\section{Conclusion}

Four sociodemographic variables (low education, middle education, living with parents, and being a chief wage earner in the family) emerged as positive significant predictors of work-related stress. Appropriate individual and group interventions (educational, counseling and psychotherapy) for vulnerable employees at risk of developing work-related stress problems need to be provided to affected employees to alleviate the problem. In addition, further research that incorporates interviews with probes was desired to gain more insights on this problem and its possible solutions.

\section{Limitations of the Study}

The present study had two main limitations. First, an interview component with probes was needed to explore further the participants' responses from the quantitative survey. Second, the number of private sector employees who participated was too small $(n=38)$. Future research should address both of these concerns. Despite these shortcomings, the current study's findings have practical significance that may be relevant to policy-makers and researchers in Brunei and elsewhere.

\section{References}

Andrews, B., \& Wilding, J. M. (2004). The relation of depression and anxiety to life-stress and achievement in students. British Journal of Psychology, 95(4), 509-521. https://doi.org/10.1348/0007126042369802

Bouteyre, E., Maurel, M., \& Bernaud, J.-L. (2007). Daily hassles and depressive symptoms among first year psychology students in France: the role of coping and social support. Stress and Health, 23(2), 93-99. https://doi.org/10.1002/smi.1125

Bradshaw, L., \& Mundia, L. (2005). Understanding preservice teachers' construct of disability: a metacognitive process. Disability and Society, 20(5), 563-574. https://doi.org/10.1080/09687590500156329

Bradshaw, L., \& Mundia, L. (2006). Attitudes to and concerns about inclusive education: Bruneian inservice and preservice teachers. International Journal of Special Education, 21(1), $35-41$.

Braithwaite, V. A., \& Law, H. G. (1985). Structure of human values: testing the adequacy of the Rokeach value survey. Journal of Personality and Social Psychology, 49(1), 250-263. https://doi.org/10.1037/0022-3514.49.1.250 


\section{$\triangle$ Macrothink}

Journal of Public Administration and Governance

ISSN 2161-7104

Chand, M. B., Upadhyay, B. P., \& Maskey, R. (2012). Biogas option for mitigating and adaptation of climate change. Rentech Symposium Compendium, 1, 5-9.

Department of Economic Planning and Development. (2015). Labor force survey 2014: preliminary report. Bandar Seri Begawan: Prime Minister's Office.

Folkman, S., \& Lazarus, R. S. (1988). Manual for the Ways of Coping Questionnaire, Consulting Psychologists Press, Palo Alto, CA. https://doi.org/10.1037/t06501-000

Haq, F. S., \& Mundia, L. (2012). Comparison of Brunei pre-service student teachers' attitudes to inclusive education and specific disabilities: Implications for teacher education. Journal of Educational Research, 105(5), 366-374. Routledge/Francis \& Taylor. http://dx.doi.org/10.1080/00220671.2011.627399

Jamadin, N., Mohamad, S., Syarkawi, Z., \& Noordin, F. (2015). Work-family conflict and stress: evidence from Malaysia. Journal of Economics, Business and Management, 3(2), 309-312. https://doi.org/10.7763/JOEBM.2015.V3.200

Jex, S. M. (2002). Organizational Psychology: A Scientist-Practitioner Approach, John Wiley \& Sons, New York, NY.

Keaney, M., \& Mundia, L (2014). Foreign language learners' motivation and its effects on their achievement: Implications for effective teaching of students studying Japanese at Universiti Brunei Darussalam. International Education Studies, 7(9), 122. https://doi.org/10.5539/ies.v7n9p122

Krejcie, R. V., \& Morgan, D. W. (1970). Determining sample size for research activities. Educational and Psychological Measurement, 30(3), 607-610. https://doi.org/10.1177/001316447003000308

Leka, S., Griffiths, A., \& Cox, T. (2004). Work Organization and Stress: Systematic Problem Approaches for Employers, Managers and Trade Unions Representatives. Series No 3, Institute of Work, Health \& Organizations, University of Nottingham, Nottingham, UK.

Lovibond, P. F., \& Lovibond, S. H. (1995). The structure of negative emotional states: comparison of the depression anxiety stress scales (DASS) with the beck depression and anxiety inventories. Behaviour Research and Therapy, 33(3), 335-343. https://doi.org/10.1016/0005-7967(94)00075-U

Maslach, C., \& Jackson, S. E. (1986). Maslach Burnout Inventory Manual, Consulting Psychologist Press, Inc, Palo Alto, CA.

Mundia, L (2015). The Relationship between Personality and Emotional Intelligence: An Exploratory Case of Brunei Student Teachers. Mediterranean Journal of Social Sciences, $6(6$ S1), 133. https://doi.org/10.5901/mjss.2015.v6n6s1p133

Mundia, L. (2006). Aggressive behavior among Swazi upper primary and junior secondary school students: implications for ongoing educational reforms concerning inclusive education. International Journal of Special Education, 21(3), 58-67. 
Mundia, L. (2007). Early childhood education in Swaziland and Brunei Darussalam: goals, achievements and challenges. Early Child Development and Care, 177(2), 151-158. http://dx.doi.org/10.1080/03004430500375885

Mundia, L. (2009). Implementation of inclusive education in Brunei Darussalam: Review of possible implications on school counsellors. Electronic Journal for Inclusive Education, Volume 2 Number 4. Spring / Summer2009 Issue. Available online: http://www.cehs.wright.edu/ prenick/Spring_Summer09_Edition/spr_sum09.html

Mundia, L. (2010a). Prevalence of depression, anxiety and stress in Brunei student teachers. Internet Journal of Mental Health, 6(2). https://doi.org/10.5580/18c7

Mundia, L. (2010b). Brunei trainee teachers' coping strategies for stressful situations. $\begin{array}{lllll}\text { International Journal of Psychological } & \text { Studies, } & 2(1), & \text { 79-88. }\end{array}$ https://doi.org/10.5539/ijps.v2n1p79

Mundia, L. (2010c). Problems in learning mathematics: Comparison of Brunei junior high school students in classes with and without repeaters. Journal of Mathematics Research, 2(3), 150-160. https://doi.org/10.5539/jmr.v2n3p150

Mundia, L. (2010d). Implementation of SPN21 curriculum in Brunei Darussalam: A review of selected implications on school assessment reforms. International Education Studies, 3(2), 119-129. https://doi.org/10.5539/ies.v3n2p119

Mundia, L. (2011a). Effects of psychological distress on academic achievement in Brunei student teachers: Identification challenges and counseling implications. Higher Education Studies, 1(1), 51-63. https://doi.org/10.5539/hes.v1n1p51

Mundia, L. (2011b). Social desirability, non-response bias and reliability in a long self-report measure: Illustrations from the MMPI-2 administered to Brunei student teachers. Educational Psychology: An International Journal of Experimental Educational Psychology, 31(2), 207-224. http://dx.doi.org/10.1080/01443410.2010.545049

Mundia, L. (2012a). The mental health profiles of student teachers: Relevance to teacher education and in identifying potential future teacher problems. The Internet Journal of World Health and Societal Politics, 7(2). https://doi.org/10.5580/2c75

Mundia, L. (2012b). The role of cognitive behavior therapy in fighting non-adherence to medical advice maintained by fear of drug side-effects in a man with cholesterol, obesity and hypertension problems. The Internet Journal of Health, 13(1). https://doi.org/10.5580/2c41

Mundia, L. (2012c). The Assessment of Mathematics Learning Difficulties in a Primary Grade 4 Child with High Support Needs: Mixed Methods Approach. International Electronic Journal of Elementary Education, 4(2), 347-366.

Mundia, L. (2012d). Assessment of GenNEXT learning outcomes at the University of Brunei Darussalam: A qualitative review of selected opportunities, benefits and challenges in human resource development. Journal of International Education and Leadership, 2(3). 
Mundia, L. (2012e). Policy changes in Brunei teacher education: Implications for the selection of trainee teachers. The Education Forum, 76(3), 326-342. https://doi.org/10.1080/00131725.2012.682489

Mundia, L. (2013). Relationship between Mental Health and Teaching: Evidence from Brunei Trainee Teachers. International Journal of Mental Health, 42(2/3), 73-98. https://doi.org/10.2753/IMH0020-7411420205

Mundia, L. (2017). How Brunei trainee teachers cope with distress: Counseling implications. BMC Research Notes, 10:596. https://doi.org/10.1186/s13104-017-2922-0

Mundia, L. (2019a). Satisfaction with work-related achievements in Brunei public and private sector employees. Cogent Management \& Business, 6(1). https://doi.org/10.1080/23311975.2019.1664191

Mundia, L. (2019b). Interpersonal Trust in Brunei Public and Private Sector Employees. In: Farazmand, A. (ed) Global Encyclopedia of Public Administration, Public Policy, and Governance. https://doi.org/10.1007/978-3-319-31816-5

Mundia, L., \& Metussin, H. (2019). Exploring factors that improve mathematics achievement in Brunei. Studies in Educational Evaluation, 60, 214-222. https://doi.org/10.1016/j.stueduc.2018.10.003

Mundia, L., \& Bakar, H. (2010). The suitability of the EPQ-R short scale for counseling Brunei student teachers when administered in English and Malay languages. Compare, 40(5), 641-658. http://dx.doi.org/10.1080/03057920903478654

Osipow, S. H., \& Spokane, A. R. (1987). Occupational Stress Inventory: Manual Research Version, Psychological Assessment Resources, Odessa, FL.

Park, J. (2008). Work stress and job performance. Perspectives on Labour and Income, 20, 7-19.

Peacock, E. J., \& Wong, P. T. P. (1990). The stress appraisal measure (SAM): A multidimensional approach to cognitive appraisal. Stress Medicine, 6(3), 227-236. https://doi.org/10.1002/smi.2460060308

Porter, L. W., \& Steers, R. M. (1973). Organizational, work, and personal factors in employee turnover and absenteeism. Psychological Bulletin, 80(2), 151-176. https://doi.org/10.1037/h0034829

Robinson, J. P., Shaver, P. R., \& Wrightsman, L. S. (1991). Measures of Personality and Social Psychological Attitudes - Volume I, Academic Press, San Diego, CA.

Rokeach, M. (1967). Value Survey, Halgren Tests, Sunnyvale, CA.

Rotter, J. B. (1967). A new scale for the measurement of interpersonal trust1. Journal of Personality, 35(4), 651-665. https://doi.org/10.1111/j.1467-6494.1967.tb01454.x

Selye, H. (1974). Stress without Distress, J.B. Lippincott Publishers, Philadelphia, PA. 


\section{Macrothink}

Journal of Public Administration and Governance

ISSN 2161-7104

2019, Vol. 9, No. 4

Tait, K., Mundia, L., Fung, F., \& Wong, C. (2014). The impact of traditional Chinese beliefs, stigma and local school service provision on the coping strategies of parents of children with Autism Spectrum Disorders in Hong Kong. Journal of the International Society for Teacher Education, 18(1), 16-25.

Tait, K., \& Mundia, L. (2012b). The impact of a child with autism on the Bruneian family system. International Journal of Special Education, 27(3), 1-14.

Tait, K., \& Mundia, L. (2012a). Preparing teachers to meet the challenges of inclusive education in Negara Brunei Darussalam. In C. I. Forlin (Ed.), Future directions for inclusive teacher education: An international perspective (pp. 60-69). Hong Kong: Routledge/Francis \& Taylor.

Tait, K., \& Mundia, L. (2014). A Comparison of Brunei and Hong Kong - SAR Student Teachers' Self-efficacy in Implementing Inclusive Education Practices: Implications for Teacher Education. Asian Social Science, 10(1), 51-60. https://doi.org/10.5539/ass.v10n1p51

Tait, K., Mundia, L., \& Fung, F. (2014). Raising Young Children with Autism Spectrum Disorders in Hong Kong: The Impact of Cultural Values and Stigma on Chinese Parents' Coping strategies. International Journal of Advances in Social Science and Humanities, 2(1), 07-157.

The Social Research Centre \& Australian National University (2012). World values survey 2012. Available

at: http://politicsir.cass.anu.edu.au/sites/politicsir.anu.edu.au/files/world-values-survey-2012-que stionnaire.pdf.

Yamane, T. (1967). Elementary Sampling Theory, Prentice-Hall, Englewood Cliffs, NJ.

Yusuf, N. M., \& Mundia, L. (2014). The status of counseling in Brunei prisons: Qualitative exploratory case study. Journal of Sociological Research, 5(1), 24-39.

\section{Copyright Disclaimer}

Copyright for this article is retained by the author(s), with first publication rights granted to the journal.

This is an open-access article distributed under the terms and conditions of the Creative Commons Attribution license (http://creativecommons.org/licenses/by/4.0/). 